\title{
Educação e participação: uma investigação das perspectivas teóricas brasileiras
}

\author{
Education and participation: \\ na investigation of brazilian theoretical perspectives \\ Educación y participación: \\ uma investigación de las perspectivas teóricas brasileñas \\ TAUÃ CARVALHO DE ASSIS \\ ORCID iD: https://orcid.org/0000-0003-0484-7893 \\ Rede Municipal de Educação de Jataí - Goiás. \\ MARIA DA GLÓRIA GOHN \\ ORCID iD: https://orcid.org/0000-0001-5791-6114 \\ Universidade Estadual de Campinas.
}

\begin{abstract}
Resumo: O trabalho tem por objetivo geral identificar e problematizar as perspectivas teóricas brasileiras sobre a participação sociopolítica na educação. Para isso, recorremos ao mapeamento dos artigos publicados sobre a temática em três revistas especializadas em educação: Revista Brasileira de Educação, Revista Brasileira de Política e Administração da Educação e, Revista Brasileira de Estudos Pedagógicos. Concluímos que a participação tem sido descrita, nas publicações analisadas, a partir de quatro perspectivas distintas, que alteram desde sua concepção até sua forma de atuação e abrangência.
\end{abstract}

Palavras-chave: Participação sociopolítica. Educação. Produção teórica brasileira.

\begin{abstract}
The paper aims to problematize the Brazilian theoretical perspectives about socio-political participation. For that, we resorted to articles published on the subject in three specialized journals in education: Revista Brasileira de Educação, Revista Brasileira de Política e Administração da Educação, and Revista Brasileira de Estudos Pedagógicos. We conclude that participation has been described, in the publications analyzed, from four different perspectives that change from its conception to its form of operation and scope.
\end{abstract}

Keywords: Socio-political participation. Education. Brazilian theoretical production.

Resumen: El trabajo tiene como objetivo general identificar y problematizar las perspectivas teóricas brasileñas sobre la participación sociopolitica en la educación. Para eso, mapeamos articulos publicados sobre el tema en tres revistas especializadas en educación: Revista Brasileira de Educação, Revista Brasileira de Politica e Administração da Educação e Revista Brasileira de Estudos Pedagógicos. Concluimos que la participación ha sido descrita en las publicaciones analizadas, desde cuatro perspectivas diferentes que cambian desde su concepción hasta su forma de actuación y alcance.

Palabras-clave: Participación sociopolitica. Educación. Producción teórica brasileña. 


\section{INTRODUÇÃO}

Inúmeros estudos da literatura brasileira, especialmente aqueles dedicados à política educacional, apontam os anos 90 como a década da implementação do ideário neoliberal na formulação e execução das políticas públicas no país (LIBÂNEO; OLIVEIRA; TOSCHI, 2003).

Paradoxalmente, e inserido no contexto político e econômico das reformas do estado, do encolhimento de suas áreas de atuação, por meio das operações de desestatização de variadas empresas públicas, da institucionalização das parcerias público-privadas, entre outras medidas difundidas pela Escola de Chicago, é que a temática da participação adquire maior relevância e visibilidade no debate político no Brasil.

A luta pelo direito de participar na definição das políticas públicas sempre esteve presente na história brasileira e, tardiamente, foi constituído enquanto direito político da sociedade civil ${ }^{1}$. Findado oficialmente o regime militar em 1985, na tentativa de superação da herança política autoritária e busca de novas alternativas para as relações Estado-Sociedade Civil, a nova Constituição, promulgada em 1988, tratou de reafirmar os direitos civis, políticos e sociais. Nesse espectro, inclui-se o direito à participação social.

No campo da educação, o direito à participação passou a ser expresso, principalmente, na forma dos princípios da gestão democrática e do controle social. Em desdobramento, ao longo do tempo, surgiram instâncias coletivas de formulação e de regulação das políticas e das instituições educacionais que passaram a contar com espaços destinados à participação da sociedade civil: conselhos escolares, conselhos gestores, conselhos de políticas públicas, conselhos municipais de educação, fóruns de educação, conferências de educação, audiências públicas, conselhos de controle social dos fundos educacionais.

Este trabalho pretende identificar e problematizar as perspectivas teóricas brasileiras sobre a participação sociopolítica na educação e, assim, contribuir com o debate sobre a participação da sociedade civil no campo da educação, buscando investigar a existência ou não de um ou mais discurso(s) educacional(is) brasileiro(s) sobre essa relação. Inventariamos e analisamos a produção científica acerca da relação participação-educação editada e publicada por três dos maiores periódicos especializados da área da educação do país, a saber: a Revista Brasileira de Educação (RBE), a Revista Brasileira de Política e Administração da Educação (RBPAE) e a Revista Brasileira de Estudos Pedagógicos (RBEP). 
O artigo está dividido em três seções distintas. A primeira, trata das questões metodológicas da pesquisa, ressaltando os parâmetros utilizados, as fontes e nossa motivação de pesquisa. Em seguida, apresentamos os resultados do mapeamento empreendido. Por último, apresentamos as conclusões discutindo com o conteúdo dos artigos em tela.

\section{QUESTÕES METODOLÓGICAS}

O objetivo desta seção é o de evidenciar o caminho metodológico adotado no curso de desenvolvimento da pesquisa. Os resultados e as conclusões aqui apresentados se devem aos limites estabelecidos para a investigação. São, assim, frutos destes.

A motivação para esta pesquisa é derivada de uma pesquisa mais ampla que pretende compreender como a relação participação social-educação se estabelece no nível local, no contexto das políticas públicas educacionais. Outro fator motivador foi a atual legislação educacional, que concebe a participação da sociedade civil como fator determinante para a promulgação de algumas das políticas públicas da área. Neste quesito, pode-se notar, em especial relevo, os planos decenais de educação, independentemente de sua esfera administrativagovernamental.

Sobre a participação, adota-se neste artigo a análise e o conceito de Gohn (2018) que diz:

O entendimento dos processos de participação da sociedade civil e sua presença nas políticas públicas nos conduz ao entendimento do processo de democratização da sociedade. O resgate dos processos de participação leva-nos, portanto, às lutas sociais que têm sido travadas pela sociedade para ter acesso aos diretos sociais e à cidadania. Neste sentido, a participação é, também, lutas por melhores condições de vida e aos benefícios da civilização [...] a participação objetiva fortalecer a sociedade civil para a construção de caminhos que apontem para uma nova realidade social, sem injustiças, exclusões, desigualdades, discriminações etc. O pluralismo é a marca desta concepção de participação na qual, os partidos políticos não são os únicos atores importantes, há que se considerar também os movimentos sociais e os agentes de organização da participação social, os quais são múltiplos. Uma gama variada de experiências associativas é considerada relevante no processo participativo tais como grupos de jovens, de idosos, de moradores de bairros etc. Os entes principais que compõem os processos participativos são vistos como "sujeitos sociais" - não se trata, portanto, de indivíduos isolados e nem de indivíduos membros de uma dada classe social. (GOHN, 2018, p. 69-71). 
Diferentes tratamentos terminológicos são dados à temática da participação pela literatura especializada. As principais encontradas são: participação social (MILANI, 2008; DOURADO; JUNIOR; FURTADO, 2016); participação política (DALLARI, 2013); participação sociopolítica (GOHN, 2011a) ${ }^{2}$. Neste trabalho adotamos, ainda, a expressão participação sociopolítica, nomenclatura adotada por Gohn (2011a), entendendo ser este o melhor termo para o estudo das relações entre a sociedade civil, o estado e a educação, pois privilegia tanto aspectos sociais quanto políticos. Segundo o dicionário Michaelis da língua portuguesa, a expressão "sociopolítico", derivada do francês sociopolitique, diz respeito àquilo que é "simultaneamente social e político; que contém elementos ou aspectos que são sociais e políticos”3.

Consequentemente, importa à participação sociopolítica a análise dos elementos sociais e políticos em um mesmo plano e de forma complementar. Soma-se a isso a abrangência da observação das relações estabelecidas entre a sociedade civil e a sociedade política no tratamento da participação.

Julgamos importante compreender como a relação investigada tem sido problematizada a partir da literatura de revistas científicas da área educacional. Assim, recorremos a processos de levantamento e mapeamento dos artigos identificados por meio da metodologia estado da arte, como concebida por Romanowski e Ens (2006, p. 39)

Estados da arte podem significar uma contribuição importante na constituição do campo teórico de uma área de conhecimento, pois procuram identificar os aportes significativos da construção da teoria e prática pedagógica, apontar as restrições sobre o campo em que se move a pesquisa, as suas lacunas de disseminação, identificar experiências inovadoras investigadas que apontem alternativas de solução para os problemas da prática e reconhecer as contribuições da pesquisa na constituição de propostas na área focalizada.

Tal metodologia visa a mapear e discutir a produção científica de uma determinada área do conhecimento à luz de categorias estabelecidas, prévias ou posteriores. Além disso, contribui com o campo investigado ao evidenciar as dimensões privilegiadas do debate e também as escassezes ou lacunas temáticas. (ROMANOWSKI; ENS, 2006)

\footnotetext{
2 Durante a década de 90 , eram frequentes a utilização dos termos participação popular e participação comunitária. (GOHN, 2019)

3 Disponível em: < https://michaelis.uol.com.br/moderno-portugues/busca/portugues-brasileiro/ sociopol $\%$ C3\%ADtico/ >. Acesso em: 07 abr. 2020.
} 
Este corte metodológico visou, ainda, a apontar as possibilidades de integração das diferentes perspectivas teóricas, aparentemente autônomas; identificar duplicações ou contradições em meio à diversidade de pesquisas encontradas, mapear os referenciais teóricos que os subsidiaram e realizar apontamentos das possíveis sugestões e proposições apresentadas.

Tradicionalmente, as revisões de literatura e as pesquisas de tipo estado da arte recorrem a congressos e reuniões científicas ou a periódicos (MIRANDA; PEREIRA, 1996). Optamos por adotar os periódicos científicos como fontes de consulta por entendermos que, na atualidade, muitas pesquisas já têm se dedicado tanto às produções de pós-graduação quanto às de congressos e eventos científicos.

De acordo com Miranda e Pereira (1996, p. 376), o periódico científico, como veículo de comunicação do conhecimento, tem por finalidade a divulgação dos saberes que se originam das atividades de pesquisa. "O periódico cumpre funções de registro oficial público da informação, mediante a reconstituição de um sistema de editor-avaliador e de um arquivo público - fonte para o saber científico."

De tal forma, elegemos três periódicos especializados em educação: (i) a Revista Brasileira de Educação (RBE), com publicações a partir de 1995, por ser mantida pela maior associação brasileira de pesquisadores educacionais, a Associação Nacional de Pós-Graduação e Pesquisa em Educação (Anped); (ii) a Revista Brasileira de Política e Administração da Educação (RBPAE), que tem como mantenedora a Associação Nacional de Política e Administração da Educação (Anpae), agremiação que reúne pesquisa educacional especializada em política, administração e gestão da educação; e (iii) a Revista Brasileira de Estudos Pedagógicos (RBEP), do Instituto Nacional de Estudos e Pesquisas Educacionais Anísio Teixeira (Inep), autarquia vinculada ao Ministério da Educação.

Nossa escolha foi motivada pela hipótese de que, nessas revistas, a temática da participação na política educacional apareceria em relevo, visto que representam duas associações de pesquisadores da educação - uma de amplo espectro, contando com um Grupo de Trabalho para o tratamento das políticas educacionais (GT-05), e a outra sendo especializada neste recorte - e, a terceira, por ser o periódico científico do órgão regulador da educação nacional.

Eleitos os periódicos a serem mapeados, utilizamo-nos de seus sítios eletrônicos na base de dados Scientific Electronic Library Online (SciELO) e Scielo Educ@ - Fundação Carlos Chagas. Não limitamos um recorte temporal, a priori, mas preferimos adotar a busca em todos os volumes disponíveis eletronicamente 
na base de dados ${ }^{4}$. A RBE tinha disponíveis seus volumes a partir do ano $2000^{5}$. A RBPAE disponibiliza seus números desde 1983, seu primeiro volume, contudo são pesquisáveis pelo mecanismo de busca do site apenas os números a partir dos anos $2000^{6}$. Já a RBEP tem seus números disponíveis a partir da publicação do ano de $2012^{7}$.

Em seguida, buscamos o termo "participação" nos mecanismos que cada sítio apresenta para pesquisa em seu acervo bibliográfico. Todos os resultados encontrados na busca foram tabulados: 42 ocorrências na RBE, 28 ocorrências na RBPAE e 4 ocorrências na RBEP, somando 74 artigos iniciais.

Logo após, mapeamos os artigos encontrados observando: título; autor(a/es/as); ano de publicação; objeto de pesquisa; concepção de participação; referenciais teóricos de/sobre participação; metodologia anunciada; ênfase de análise.

Aplicamos, por fim, critérios de exclusão para os artigos. Foram quatro: (i) quando tratava de reflexões sobre experiências estrangeiras, porque não representavam uma perspectiva brasileira; (ii) quando se tratava de estudo estrangeiro sobre a experiência brasileira, pelo mesmo motivo; (iii) quando se tratava de problematização regional/continental porque extrapolavam o recorte geográfico; e (iv) quando os escritos eram externos à temática e/ou à forma, como editoriais, resenhas, ou quando o termo "participação" era usado em contexto diferente do pesquisado.

Após a aplicação do critério de exclusão, vinte e sete publicações foram desconsideradas: 16 eram relatos de experiências estrangeiras; 9 eram escritos externos à temática; 1 era reflexão estrangeira sobre a realidade brasileira e 1 era reflexão sobre a América Latina como um todo. Assim, resultamos nos seguintes números: 22 artigos da RBE (47\%); 24 artigos da RBPAE (51\%); e 1 artigo da RBEP (2\%), resultando 47 trabalhos para análise. Poderiam essas publicações indicar a confluência de uma perspectiva teórica educacional brasileira sobre a participação sociopolítica no campo da educação?

\footnotetext{
4 A pesquisa aos sítios eletrônicos foi realizada entre os dias 6 e 10 de janeiro de 2020. Todas os volumes disponíveis nesse período entraram em nossa busca.

5 Disponível em: $\quad<\quad$ http://www.scielo.br/scielo.php?script=sci_issues\&pid=14132478\&lng=pt\&nrm=iso $>$. Acesso em: 6 jan. 2020.

6 Disponível em: < https://seer.ufrgs.br/rbpae/issue/archive>. Acesso em: 10 jan. 2020.

7 Disponível em: $<\quad$ http://www.scielo.br/scielo.php?script=sci_issues\&pid=21766681\&lng=pt\&nrm=iso $>$. Acesso em: 8 jan. 2020.
} 


\section{A PARTICIPAÇÃO NA EDUCAÇÃO PELOS PERIÓDICOS}

Os 47 artigos encontrados na pesquisa foram publicados nas revistas selecionadas entre os anos 2000 e 2019, sendo que nenhum trabalho sobre a temática foi registrado nos anos 2002 e 2003. Segue abaixo a distribuição temporal das publicações.

\section{Gráfico 1 - Ano de publicação dos artigos}

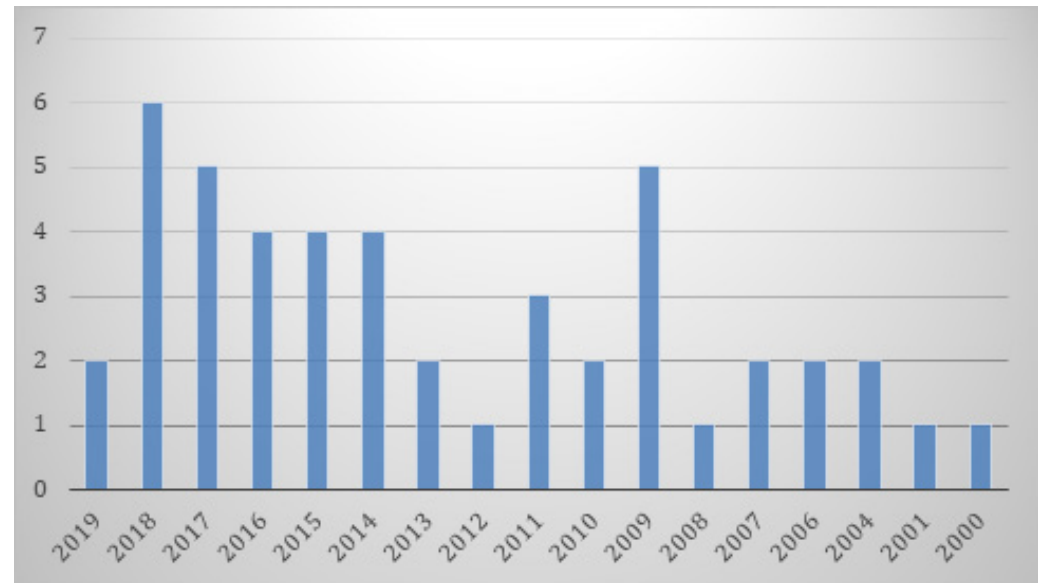

Fonte: Os autores.

É interessante notar que é a partir do ano de 2009 que a temática aparecesse em maior número nas revistas RBE, RBPAE e RBEP, sendo 25 deles publicados a partir de 2014, evidenciando um aumento de interesse na temática da participação na educação.

Os anos em que a temática apresentou maior número de artigos publicados foi em 2018 (6 trabalhos), seguido dos anos 2017 e 2009 (5 trabalhos cada). Uma possível lógica histórica explicativa para os números de trabalhos serem maiores nesses anos talvez resida no fato de que, naquele momento, os canais de participação começaram a ser desativados ${ }^{8}$. Ainda que retratem experiências passadas, consideramos que publicá-los em 2017-2018 pode ser considerado como uma forma de resistência dos pesquisadores à ação de esvaziamento. 
$\mathrm{Na}$ maioria dos casos, os trabalhos não guardam relação direta com os movimentos sociais, políticos e educacionais do momento de suas publicações. Uma exceção a ser registrada é o trabalho de Haddad (2009), que reflete sobre a participação da sociedade civil brasileira na $6^{a}$ Conferência Internacional de Jovens e Adultos (CONFINTEA VI), realizada em 2009, mesmo ano da publicação.

Em nosso levantamento, registramos também o eixo de análise das produções publicadas. As categorias foram elaboradas a posteriori, de acordo com os trabalhos que localizamos. Os artigos foram agrupados em seis eixos distintos: (i) análise de curso ou programa, quando se tratava de analisar a execução/efeitos de um programa governamental ou curso em um contexto específico, por exemplo, em Nascimento (2018), que problematiza o Programa de Governança Local implantado em Porto Alegre, a partir de 2005; (ii) análise de política educacional, quando o trabalho problematizava uma política educacional em um contexto de larga escala, por exemplo, Monte (2000), que escreve sobre os processos de formalização da educação indígena; (iii) análise de produção bibliográfica e documental, como em Brzezinski (2013) que retrata os princípios da Carta de Goiânia/IV CBE; (iv) análise de práticas pedagógicas/escolares, como em Silva (2014), que pesquisou a participação e engajamento de alunos indígenas no processo escolar; (v) análise de crenças, percepções e representações sociais, quando os trabalhos abordavam predominantemente a visão dos sujeitos sobre a temática, como em Pereira (2007), que investigou a percepção de trabalhadores rurais sobre sua participação e vivência em programas educacionais; e (vi) análise histórica de entidade ou movimento, como o trabalho de Pucci (2007) sobre o Fórum de Coordenadores de Programas de Pós-Graduação em Educação.

\section{Gráfico 2-Eixos de análises dos artigos analisados}

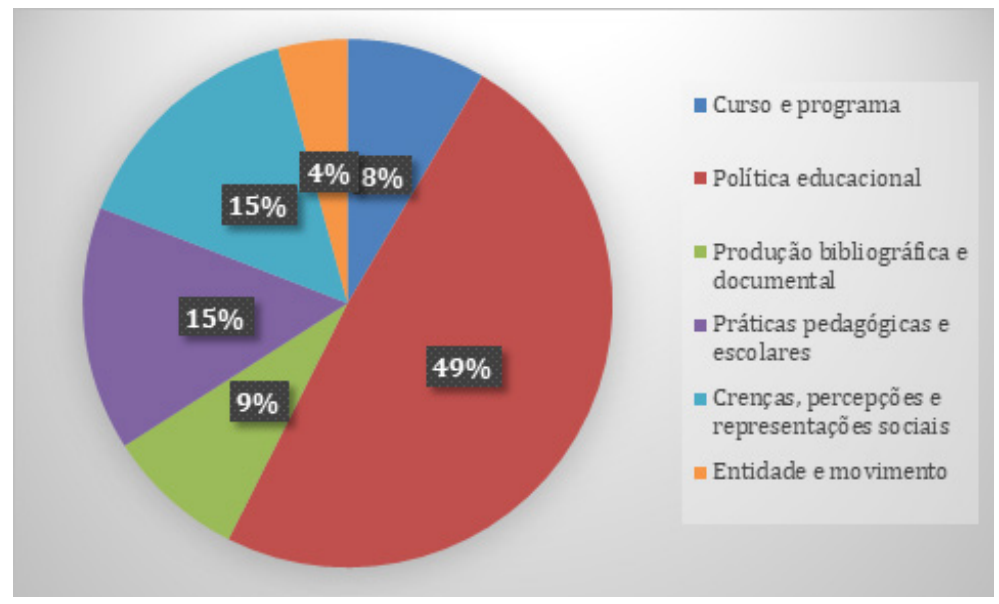

Fonte: Os autores. 
A maioria dos trabalhos, 23 deles, se concentrou na análise de determinada política educacional. Tal dado sugere a preferência de análise pelas proposições e/ou resultados de uma política pública instituída na área da educação. Em seguida, as análises das práticas pedagógicas e escolares e de crenças, percepções e representações sociais contam com sete trabalhos cada. $\mathrm{Na}$ análise de produção bibliográfica e documental, somaram-se quatro trabalhos. Quatro trabalhos se inserem nas análises de cursos e programas e dois na análise de entidade e movimento.

As referências teóricas utilizados para debater a temática da participação nos artigos também foram objeto de inventário. Nos preocupamos em entender a utilização dos referenciais da participação porque entendemos que essa percepção nos ajudaria a compreender as concepções dadas ao termo participação na produção do conhecimento brasileiro.

Do universo de artigos alvos de análise deste estudo, foram feitas 78 referências a autores que debatem a participação de modo amplo, não somente no campo da educação.

\section{Quadro 1 - Referências mais utilizadas nos artigos}

\begin{tabular}{|c|c|c|}
\hline Referenciais & Número de referências registradas & Anos dos trabalhos referenciados \\
\hline & & 1989 \\
& & 2001 \\
& & 2006 \\
Maria da Glória Marcondes Gohn & & 2008 \\
& & $2009 \mathrm{a}$ \\
& & $2009 \mathrm{~b}$ \\
& & $2009 \mathrm{c}$ \\
& & $2010 \mathrm{a}$ \\
& & $2010 \mathrm{~b}$ \\
& & 2011 \\
\hline \multirow{3}{*}{ Evelina Dagnino } & & 1994 \\
& & 2004 \\
& & Panfichi) \\
\hline \multirow{2}{*}{ Licínio Lima } & & 1998 \\
& & 2000 \\
& 3 & 2003 \\
\hline \multirow{2}{*}{ Pedro Demo } & 3 & 1985 \\
& & 1988 \\
& & 2009 \\
\hline
\end{tabular}




\section{Quadro 1 - Referências mais utilizadas nos artigos}

\begin{tabular}{|c|c|c|}
\hline Referenciais & Número de referências registradas & Anos dos trabalhos referenciados \\
\hline Vitor Henrique Paro & 3 & $\begin{array}{l}1997 \\
2002 \\
2011\end{array}$ \\
\hline Carlos Roberto Jamil Cury & 2 & $\begin{array}{l}1997 \\
1998\end{array}$ \\
\hline Jacques Rancière & 2 & $\begin{array}{l}1995 \\
1996\end{array}$ \\
\hline Juan Enrique Díaz Bordenave & 2 & $\begin{array}{l}1985 \\
1994\end{array}$ \\
\hline Luiz Fernandes Dourado & 2 & $\begin{array}{l}2000 \\
2006\end{array}$ \\
\hline
\end{tabular}

Fonte: Os autores.

O levantamento de referências nos permitiu identificar os estudiosos que têm fomentado os debates acerca da participação na educação. Como evidenciado no quadro acima, o conjunto da obra de Gohn tem sido referencial central nos artigos analisados para se problematizar essa relação. Acreditamos que a explicação para isso pode ser encontrada no volume da obra da estudiosa e em sua reflexão contínua, ao longo dos anos, acerca da participação no Brasil.

Em seguida, aparecem com 3 referências cada: Dagnino, Lima, Demo e Paro, autores que também contam com estudos sobre a participação. Uma diferenciação que se pode fazer entre estes autores é a de que Dagnino e Demo têm problematizado em seus escritos a participação de uma forma mais ampla e de caráter societário, enquanto Lima se preocupa em pensar a estrutura da escola e Paro tem como eixo de reflexão a gestão democrática.

Com duas citações, temos Cury, Rancière e Bordenave, que proporcionam um debate já clássico acerca da temática e, Dourado, em anos mais recentes, de forma articulada com as discussões acerca dos Planos Nacionais de Educação.

Outros 46 autores aparecem referenciados apenas uma vez. Essa amostra é composta de autores das mais diversas correntes teóricas e expressões metodológicas. Importante registrar nesse contexto a presença de Alain Touraine e de Thomas Humphrey Marshall. Também é o caso de Carole Pateman, autora considerada clássica nas ciências sociais e nas discussões sobre participação e que aparece em apenas um dos artigos. 
Assim como as presenças, fez-se notar também a ausências de referencial teórico em parte das produções. Nas discussões de 21 dos artigos, não registramos nenhum referencial e/ou obra de aporte teórico sobre a temática da participação e nenhuma conceituação do termo. ${ }^{9}$

Uma outra categoria de nossa análise da produção bibliográfica foi a concepção de participação que o artigo apresentava em seu bojo. Pretendemos, com essa categoria, inventariar e entender como os pesquisadores(as) brasileiros da temática participação-educação têm compreendido o termo participação. Assim, essa foi uma categorização também a posteriori. Identificamos quatro perspectivas distintas: participação como envolvimento/engajamento em alguma atividade; participação como integração; participação como tomar parte nas decisões e ações escolares; e participação como tomar parte nas decisões e ações governamentais.

Julgamos ser pertinente esclarecer os significados encontrados em cada perspectiva de participação aqui anunciada por meio de recortes dos textos analisados, como forma de exemplificação. A primeira perspectiva, participação como envolvimento/engajamento em alguma atividade, foi encontrada em 9 artigos. Um exemplo é o trecho retirado do texto de Carvalho (2004, p. 96):

A questão de política educacional é se é viável incentivar a participação dos pais (cujos filhos vão mal na escola) via dever de casa, precisamente daqueles que não participam por falta de capital econômico (tempo livre, dinheiro para pagar aulas de reforço) e cultural (cultura acadêmica e conhecimento atualizado dos conteúdos curriculares).

O termo participação é utilizado para envolvimento ou engajamento em uma determinada atividade, neste caso, na tarefa de casa dos alunos de uma escola pública. Assim, não se vislumbra um horizonte para o exercício de uma participação que se queira social e política, mas apenas de envolvimento em uma situação/atividade muito específica e de alcance limitado.

A segunda perspectiva, a da participação como integração, também pode ser definida como o movimento de compor uma determinada população específica, como em (FERREIRA, 2018, p. 418-9):

9 Embora esse seja um resultado colateral, não explícito em nosso objetivo geral, acreditamos ser relevante propor a discussão acerca da falta de referencial teórico e/ou conceituação do termo participação, categoria alvo desta pesquisa. Nesses casos, onde não foi identificado referencial e/ou conceito, o termo é empregado em caráter difuso e sem especificidade. 
Incentivo à participação: organizar campanhas que incentivem a organização e a participação das mulheres trabalhadoras em educação; promover a participação da mulher em movimentos feministas e coletivos; lutar pela representação das mulheres em entidades sócio-políticas; incentivar a participação nas atividades da secretaria; promover atividades e ações políticas que visem inserir a mulher no mundo da política e do trabalho.

De tal forma, o termo participação veicula a ideia de uma possibilidade futura de integração a algum grupo, como um sindicato ou um setor de gênero do sindicato, um partido político ou outra organização. Identificamos nesta concepção uma fragilidade: a participação não é um "verbo", um curso da ação, mas uma vontade futura de integração. Não se preocupa com a atuação dos sujeitos em si, mas na sua integração a "entes já participativos".

O excerto a seguir, retirado de Nardi (2015) é ilustrativo da perspectiva de participação como tomar parte nas decisões e ações escolares.

Essa constatação [a existência de espaços de participação] é relevante na medida em que a formulação e a implementação de ações voltadas à promoção da participação da comunidade escolar, com vistas à democratização da gestão, não constituem um eixo específico da pesquisa, embora se tenha depositado certa expectativa de que iniciativas dessa ordem constassem dos eixos que integram a dimensão "gestão escolar". (p. 659)

São os espaços participativos intraescolares que possibilitam à comunidade influir nas decisões e ações que se desenrolam no espaço escolar. A existência normativa e real das instâncias de participação na escola é que possibilitam à comunidade tomar parte das decisões e ações de forma a instituir a gestão democrática. São exemplos apresentados pelo autor: os conselhos de classe, as Associações de Pais e Professores e as assembleias. Essa perspectiva, apesar de admitir a participação social e política da comunidade escolar, exclui o espectro da ampla participação da sociedade civil em prol do corpo social que se vincula a uma determinada instituição escolar. Outro aspecto a se considerar é que, na literatura e na legislação pós-88, as iniciativas de participação escolar, por vezes, figuram como medidas de gestão democrática e de controle social da escola e de sua qualidade, não sendo ligadas diretamente ao poder de design das políticas educacionais.

A última perspectiva teórica, participação como tomar parte nas decisões e ações governamentais, se refere à possibilidade normativa ou real da sociedade civil como um todo de participar do processo decisório em educação, de modo mais amplo do que apenas em uma instituição específica, mas na definição do conteúdo e da forma da política educacional, como registrou Dourado (2009, p. 374): 
Considerando as condições objetivas da população, neste país historicamente demarcado por forte desigualdade social (revelada por indicadores sociais preocupantes) e que carece de amplas políticas públicas - incluindo a garantia de otimização das políticas de acesso, permanência e gestão, com qualidade social, na educação básica e superior -, destacou-se a importância de participação política da sociedade brasileira na formulação e implementação das políticas e programas, bem como na melhoria da educação em diferentes níveis e modalidades.

Esta perspectiva, que é a que soma maior número de artigos segundo os parâmetros adotados nesta pesquisa, vislumbra, por um lado, uma participação ampla para todos da sociedade civil e não apenas para os diretamente ligados ao funcionamento diário de uma escola e, por outro lado, uma participação que influa no desenho das políticas educacionais.

\section{Gráfico 3 - Perspectivas teóricas de participação na educação}

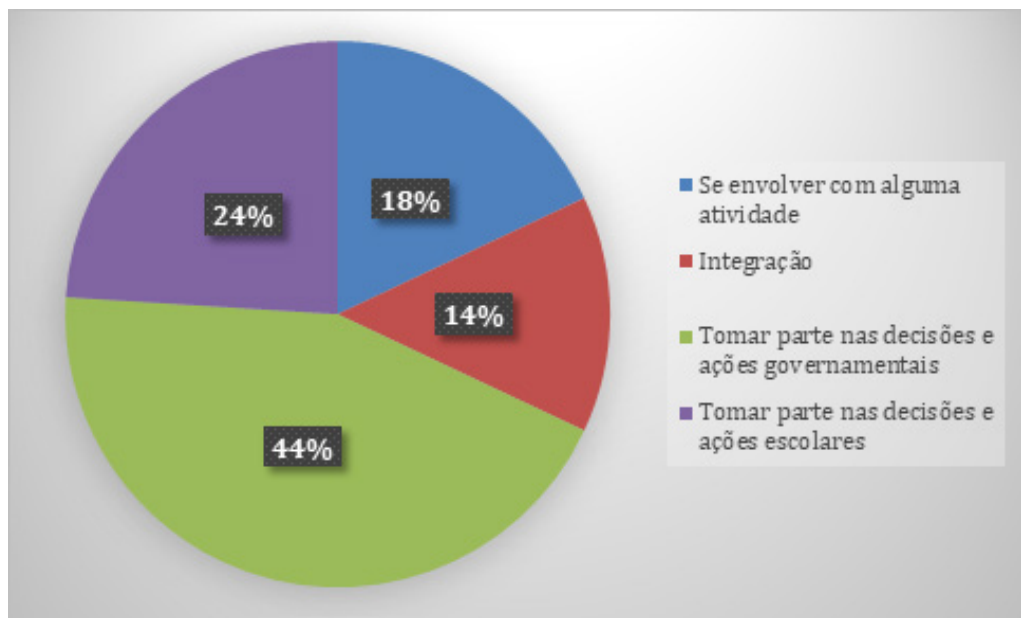

Fonte: Os autores.

O gráfico acima representa imageticamente as quatro perspectivas distintas encontradas nos trabalhos analisados nesta pesquisa. Juntas, as perspectivas anunciadas somam 50 menções, isso porque três artigos retratam a participação em mais de uma perspectiva, são eles: Oliveira (2013), Cavalcanti (2016) e De Souza (2010).

Os dados acima indicam que os pesquisadores brasileiros têm entendido, na maioria dos trabalhos analisados, que a participação na educação está relacionada com a possibilidade de tomar parte nas decisões e ações governamentais e escolares. As duas perspectivas compartilham a ideia matriz de abertura e democratização da educação, seja nas políticas educacionais ou nas organizações escolares. Em 
outras palavras, entendem a participação da sociedade civil/comunidade escolar como princípio fundamental nas definições das políticas públicas educacionais e/ ou das gestões públicas educacionais.

Neste sentido, tomar parte vai além da ideia de integração e de composição de determinada população. As perspectivas de tomar parte nas decisões e ações governamentais e escolares já pressupõem estar integrado e admite ainda a intervenção no processo decisório com voz e/ou voto.

\section{UM BALANÇO DA PRODUÇÃO BRASILEIRA}

Em linhas gerais, este estudo refutou nossa hipótese inicial. Pensávamos que as três revistas selecionadas concentrariam grande número de produções sobre a temática da participação na educação. Não foi o que encontramos. Em todo o período pesquisado, 74 trabalhos contavam com a inserção do termo e apenas 24 eram artigos e tratavam especificamente do contexto brasileiro.

Decorrente disso, pressupomos que as revistas em que a temática investigada apareceria em maior relevo seriam da Revista Brasileira de Estudos Pedagógicos, por se tratar de uma publicação de autarquia vinculada ao Ministério da Educação, ou seja, a órgãos governamentais; e na Revista Brasileira de Política e Administração da Educação, publicada pela ANPAE, entidade dedicada aos estudos e pesquisas em política, administração e gestão da educação. Todavia, foi na Revista Brasileira de Educação, da ANPED, que encontramos o maior número de artigos sobre o assunto.

Os dados obtidos neste estudo nos permitem afirmar que o termo participação foi instrumentalizado na literatura analisada, de forma polissêmica e diversa. Em grande parte dos casos, o termo foi utilizado e debatido sem qualquer referenciação teórica ou explicitação do conceito. Foi o que aconteceu em 21 dos artigos. Nestes casos, o termo ganhou conotações de sentido pessoal dos autores em detrimento de seu significado social e teórico.

Apesar disso, pudemos categorizar quatro perspectivas teóricas utilizadas de forma recorrente pela literatura brasileira analisada aqui: (i) participação como integração; (ii) participação como envolvimento/engajamento em alguma atividade; (iii) participação como tomar parte nas decisões e ações escolares; e (iv) participação como tomar parte nas decisões e ações governamentais.

Apesar de possuírem nomenclaturas bastante próximas, entendemos que as duas últimas perspectivas possuem significados bem diferentes e longínquos, apesar de ambas estarem circunscritas em "tomar parte nas decisões e ações". É o contexto da atuação participativa que as difere. 
Embora a perspectiva tomar parte nas decisões e ações escolares proponha a participação, ela é apresentada de forma restrita e, de certa forma, utilitária. Participar das ações da instituição escolar não está aberto a todos os cidadãos, mas apenas àqueles pertencentes àquela comunidade escolar: familiares dos alunos e servidores da escola. Assim, a participação contemplada aqui é cumulativa das duas perspectivas anteriores, porque envolve tanto o exercício de integrar-se a algo, a escola, quanto se envolver em alguma atividade, a gestão da instituição. De outra forma, a participação assim descrita também é restrita em seu âmbito de atuação, pois se fundamenta e se encerra no contexto imediato. Em geral, nas normatizações legais e na literatura observada, essas experiências em instituições educacionais têm sido definidas a partir dos termos "gestão democrática" e "controle social" e, não pelo termo "participação".

Por outro lado, a perspectiva entendida como "tomar parte nas decisões e ações governamentais" é abrangente em seu âmbito de atuação, pois ao participar do processo decisório de uma política pública educacional, ainda que de nível municipal, afasta-se dos casos específicos para se pensar a coisa pública enquanto direito de todos e influindo no contexto mediato. Uma outra diferença é que as decisões são pensadas com teor mais político do que administrativo. Isso não quer dizer que os gestores estejam impedidos de utilizarem o processo participativo apenas como mecanismo legitimador de suas ações ou de forma funcional, mas, pelo contrário, este é um risco apresentado pela literatura e pelos artigos analisados.

Da análise dos textos dos artigos depreende-se também amplos sentidos e características atribuídas ao processo participativo, especialmente na educação. No tratamento da temática, duas abordagens distintas do tema foram identificadas, as quais denominamos locais e globais. Por locais entendemos o conjunto dos trabalhos que problematizam a questão da participação de modo circunscrito geograficamente a uma escola, a um município, a um estado ou a uma instância determinada, uma associação, um conselho, um programa governamental. De fato, a ampla maioria dos trabalhos, 44 deles, ou 93,62\% da amostra, apresentam esta abordagem: problematizam a participação apenas em um determinado local ou instância.

Existem também os trabalhos com uma abordagem mais ampla da questão que, mesmo partindo da reflexão de uma experiência particular, ampliam o debate e se utilizam de aportes teóricos da participação para pensar aquela experiência para além de seu contexto específico de pesquisa ou as contribuições dela, para a produção do conhecimento sobre a participação. Esses somaram apenas três trabalhos, ou 6,38\%, de nossa amostra. Foram eles: Costa (2001), Gohn (2011b) e Haddad (2009). 
Outro foco relevante encontrado foram as definições do advento da participação no Brasil. Alguns artigos seguem o viés da formalização da participação. Em outras palavras, sugerem que ela existe porque foi sancionada legalmente pelo estado e que hoje se traduz em mera formalidade decretada pelas reformas de Bretton Woods e organismos internacionais ou em práticas de descentralização do estado. Outros encaram que a participação, ainda que hoje esteja prevista de forma legal, é uma conquista de direitos políticos, fruto de lutas e movimentos por parte da sociedade civil.

Apesar do acumulado histórico, com períodos de alternância de experiências democráticas e autoritárias, alguns estudos chamam atenção para os fatos das experiências participativas terem histórias curtas e sofrerem de descontinuidades políticas e administrativas (PEREIRA, 2004) e da existência de dificuldades na replicação das experiências democráticas (MONTE, 2000). Neste mesmo sentido, Flach e Sakata (2016) afirmam que, embora o processo participativo já esteja dado e pareça algo de simples execução, sua efetivação no campo das políticas públicas tem se mostrado desafiador e bastante complexo.

A participação tem sido registrada como tendo duas características centrais: ser processual e ser pedagógica. Corroborando com a literatura da área, estudos apontam que o direito à participação se materializa no processo, entendendo que ela não se encerra em um resultado ou em um produto, mas que se desenvolve no decorrer dos processos participativos. O caráter educativo da participação tanto pode ocorrer "para o mal ou para o bem", pois pode propiciar o advento da governamentalidade ou propiciar o exercício político como forma de aprendizagem que se realiza na prática. (NASCIMENTO, 2018; SILVA, 2014)

Sobre a natureza dos atores, duas observações são importantes a partir dos artigos estudados. A negação da presença e da representatividade de certas populações no processo decisório das políticas educacionais, particularmente dos estudantes (FERREIRA et. al., 2014); dos deficientes (OLIVEIRA, 2013); dos indígenas (MONTE, 2000); e dos trabalhadores rurais (PEREIRA, 2007). E a importância dos movimentos sociais para a conquista dos direitos políticos, em especial, do direito à participação, propiciados por meio de dinâmicas próprias de negociação e de conflito que forçam novas pautas, marcos legais e práticas sociais. (MONTE, 2000; HADDAD, 2009; GOHN, 2011b)

Acerca da efetividade da participação, os estudos têm demonstrado que a simples consulta não garante a participação consciente dos sujeitos (FLACH; SAKATA, 2016); que as condições objetivas e materiais e a especificidade do grupo social podem inibir a participação e conduzir a uma lógica de naturalização de outros interesses (NEPOMUCENO; ARAUJO; 2019); a existência de movimentos contraditórios de ampliação e de restrição à participação (SILVA; 
DUARTE, 2017); que a efetivação da participação está marcada pelas vinculações políticas e culturais dos sujeitos ${ }^{10}$; e a existência de diferentes graus de participação que podem ir da simples consulta até ao direito de voz e voto no processo decisório. Haddad (2009) nos lembra ainda que as formas de participação têm variado no Brasil, de acordo com a conformação política dos governos estabelecidos.

O objetivo central deste trabalho foi o de identificar e analisar as perspectivas teóricas brasileiras sobre participação na educação expressas em artigos publicados nas revistas RBE, RBPAE e RBEP. Encontramos quatro perspectivas distintas de conceber a participação na educação. Em linhas gerais, apenas uma delas se apresenta de forma crítica, a saber, "participação como tomar parte nas decisões e ações governamentais"; outras duas, "participação como integração" e "participação como envolvimento/engajamento em alguma atividade", se apresentam de forma acrítica; e uma delas, "participação como tomar parte nas decisões e ações escolares", pode se apresentar de forma crítica, quando propõe, por exemplo, a tomada de decisão compartilhada com as famílias, ou acrítica, quando entende que a família participa quando se envolve apenas com a atividade para cada um de seu(s) filho(s).

Nos artigos analisados ficou evidente que, ainda que a legislação garanta o direito à participação, ela tem sido negada aos cidadãos brasileiros no planejamento educacional ou, por vezes, desconsiderada. Nota-se a ausência de estudos que investiguem a participação sociopolítica na consecução dos planos decenais de educação nacionais, estaduais e municipais, tendo em vista que essa política se instaura enquanto obrigação legal a partir do ano de $2014^{11}$.

Existe grande número de artigos que não apresentam articulação e referencial teórico com autores sobre a participação, casos que aconteceram em maior número na perspectiva participação como integração. Em outras vezes, os referenciais apontados eram autores da gestão escolar e/ou democrática. Em decorrência disso, os estudos têm, em sua grande maioria, analisado a participação apenas em contextos específicos de pesquisa e não em sua teoria e no âmbito da política educacional, evidenciando a diferença entre ser parte e ter parte.

\footnotetext{
10 Essa relação também já foi descrita por Gohn (2010).

11 A política de planos subnacionais decenais de educação foi instaurada, de forma obrigatória, pela lei 13.005, de 24 de junho de 2014 em seu artigo oitavo. Tal indução já aparecia na lei 10.172, de 9 de janeiro de 2001, mas sem definição de data de execução.
} 


\section{REFERÊNCIAS}

BRZEZINSKI, Iria. Princípios da Carta de Goiânia/IVCBE na Constituição Federal "cidadã" (CF/1988): participação da sociedade civil nas políticas educacionais. Revista Brasileira de Política e Administração da Educação Periódico científico editado pela ANPAE, [S.1.], v. 29, n. 2, nov. 2013.

CARVALHO, José Murilo de. Cidadania no Brasil: o longo caminho. 11 a ed. Rio de Janeiro: Civilização Brasileira, 2008.

CARVALHO, Maria Eulina Pessoa de. Escola como extensão da família ou família como extensão da escola? O dever de casa e as relações família-escola. Rev. Bras. Educ., [s.l.], n. 25, p. 94-104, abr. 2004. Disponível em: http://www.scielo.br/ pdf/rbedu/n25/n25a08.pdf. Acesso em: 07 abr. 2020.

CAVALCANTI, Cacilda Rodrigues. Custo Aluno Qualidade inicial, 10\% do PIB e uma nova fonte de receita: novas perspectivas para o financiamento da educação básica?. Revista Brasileira de Política e Administração da Educação Periódico científico editado pela ANPAE, [S.1.], v. 32, n. 2, p. 487 - 507, ago. 2016.

COSTA, Márcio da. Criar o público não-estatal ou tornar público o estatal? Dilemas da educação em meio à crise do Estado. Rev. Bras. Educ., Rio de Janeiro, n. 18, p. 41-51, 2001. Disponível em: http://www.scielo.br/pdf/rbedu/ n18/n18a05. Acesso em: 07 abr. 2020.

DALLARI, Dalmo de Abreu. O que é participação política. São Paulo: Brasiliense, 2013. (Coleção Primeiros Passos; 104)

DE SOUZA, Donaldo Bello de. Anais dos eventos da Anped e da Anpae (20002008) e o estado da temática gestão, autonomia escolar e órgãos colegiados. Revista Brasileira de Política e Administração da Educação - Periódico científico editado pela ANPAE, [S. 1.], v. 26, n. 3, p. 441-459, 2010. Disponível em: https://seer.ufrgs.br/rbpae/article/view/19792/11530. Acesso em: 07 abr. 2020. 
DOURADO, Luiz Fernandes. A Conferência Nacional de Educação, o Plano Nacional e a construção do Sistema Nacional de Educação. Revista Brasileira de Política e Administração da Educação - Periódico científico editado pela ANPAE, [S.1.], v. 25, n. 2, mai./ago. 2009. ISSN 2447-4193.

DOURADO, Luiz Fernandes; GROSSI JUNIOR, Geraldo; FURTADO, Roberval Angelo. Monitoramento e avaliação dos planos de educação: breves contribuições. : breves contribuições. Revista Brasileira de Política e Administração da Educação - Periódico científico editado pela ANPAE, [s.l.], v. 32, n. 2, p. 449-461, 21 ago. 2016. Disponível em: https://seer.ufrgs.br/rbpae/article/ view/67198/38375. Acesso em: 07 abr. 2020.

FERREIRA, Izabel do Rocio Costa; MOYSÉS, Samuel Jorge; FRANÇA, Beatriz Helena Sottile; CARVALHO, Max Luiz de; MOYSÉS, Simone Tetu. Percepções de gestores locais sobre a intersetorialidade no Programa Saúde na Escola. Revi. Bras. Educ., [S.1.], v. 19, n. 56, p. 61-76, mar. 2014. Disponível em: http://www. scielo.br/pdf/rbedu/v19n56/v19n56a04.pdf. Acesso em: 07 abr. 2020.

FERREIRA, Márcia Ondina Vieira et al. Abordagem das desigualdades de gênero e diversidade sexual em sindicatos de trabalhadoras/es em educação: o caso da Confederação Nacional dos Trabalhadores em Educação (CNTE). Rev. Bras. Estud. Pedagog., Brasília, v. 99, n. 252, p. 404-428, ago. 2018.

FLACH, Simone de Fátima; SAKATA, Kelly Letícia da Silva. O princípio da gestão democrática na educação pública e sua efetivação no âmbito do sistema municipal de ensino de Ponta Grossa-PR. Revista Brasileira de Política e Administração da Educação - Periódico científico editado pela ANPAE, [S.l.], v. 32, n. 2, p. 549 - 569, ago. 2016.

GOHN, Maria da Glória. Educação não formal e o educador social. Atuação no desenvolvimento de projetos sociais. São Paulo: Cortez, 2010.

GOHN, Maria da Glória. Conselhos gestores e participação sociopolítica. 4. ed. São Paulo: Cortez, 2011a. (Coleção questões de nossa época; v. 32)

GOHN, Maria da Glória. Movimentos sociais na contemporaneidade. Revista Brasileira de Educação, [s.l.], v. 16, n. 47, p. 333-361, ago. 2011b. Disponível em: http://www.scielo.br/pdf/rbedu/v16n47/v16n47a05.pdf. Acesso em: 07 abr. 2020 . 
GOHN, Maria da Glória. Potencialidades e limites da participação no federalismo brasileiro. In: FREY, Klaus; CARNEIRO, José Mário Brasiliense (orgs.). Governança multinível e desenvolvimento regional sustentável. Experiências do Brasil e da Alemanha. São Paulo: Konrad Adenauer Stiftug/ Oficina Municipal/UFABC, p. 69-90. 2018.

GOHN, Maria da Glória. Participação e democracia no Brasil: da década de 1960 aos impactos pós-junho de 2013. Petrópolis: Vozes, 2019.

HADDAD, Sérgio. A participação da sociedade civil brasileira na educação de jovens e adultos e na CONFINTEA VI. Revista Brasileira de Educação, [s.l.], v. 14, n. 41, p. 355-369, ago. 2009. Disponível em: http://www.scielo.br/pdf/ rbedu/v14n41/v14n41a13.pdf. Acesso em: 07 abr. 2020.

LIBÂNEO, José Carlos; OLIVEIRA, João Ferreira de; TOSCHI, Mirza Seabra. Educação escolar: políticas, estrutura e organização. São Paulo: Cortez, 2003. (Coleção Docência em Formação)

MILANI, Carlos R. S. O princípio da participação social na gestão de políticas públicas locais: uma análise de experiências latino-americanas e europeias. RAP Revista da Administração Pública, 42 (3), mai.-jun./2008, p. 551-579. Rio de Janeiro: FGV.

MIRANDA, Dely Bezerra de; PEREIRA, Maria de Nazaré Freitas. O periódico científico como veículo de comunicação: uma revisão de literatura. Ciência da Informação, [S.l.], v. 25, n. 3, dec. 1996.

MONTE, Nietta Lindenberg. E agora, cara pálida? Educação e povos indígenas, 500 anos depois. Rev. Bras. Educ., Rio de Janeiro, n. 15, p. 118-133, dez. 2000.

NARDI, Elton Luiz. Itinerários da participação na gestão de escolas públicas de educação básica. Revista Brasileira de Política e Administração da Educação - Periódico científico editado pela ANPAE, [S.1.], v. 31, n. 3, p. 649 - 666, set./ dez. 2015.

NASCIMENTO, CLARICE ANTUNES DO. Do governo dos homens... e das almas. Rev. Bras. Educ., Rio de Janeiro, v. 23, e230014, 2018. 
NEPOMUCENO, Aline Lima de Oliveira; ARAUJO, Maria Inêz Oliveira. Política pública e educação ambiental: aspectos conceituais e ideológicos de participação, democracia e cidadania em Sergipe. Revista Brasileira de Política e Administração da Educação - Periódico científico editado pela ANPAE, [S.1.], v. 35, n. 3, p. 941, dez. 2019.

OLIVEIRA, Cristina Borges de. Jovens deficientes na universidade: experiências de acessibilidade?. : experiências de acessibilidade?. Rev. Bras. Educ., [s.1.], v. 18, n. 55, p. 961-984, dez. 2013. Disponível em: http://www.scielo.br/pdf/rbedu/ v18n55/09.pdf. Acesso em: 07 abr. 2020.

PEREIRA, Sônia. A contribuição do homem simples na construção da esfera pública: os trabalhadores rurais de Baturité - Ceará. Rev. Bras. Educ., Rio de Janeiro, n. 26, p. 29-43, ago. 2004.

PEREIRA, Sônia. Espaços de participação e escolarização de trabalhadores rurais: construção ou destituição do direito à educação no campo?. Rev. Bras. Educ., Rio de Janeiro, v. 12, n. 35, p. 359-371, ago. 2007.

PUCCI, Bruno. Fórum dos Coordenadores de Programas de Pós-Graduação em Educação: apontamentos históricos. : apontamentos históricos. Rev. Bras. Educ., [s.l.], v. 12, n. 36, p. 424-442, dez. 2007. Disponível em: http://www.scielo. br/pdf/rbedu/v12n36/a04v1236.pdf. Acesso em: 07 abr. 2020.

ROMANOWSKI, Joana Paulin; ENS, Romilda Teodora. As pesquisas denominadas do tipo "estado da arte" em educação. Diálogo Educ., v. 6, n.19, p.37-50, set./dez. Curitiba, 2006.

SILVA, Luiz Fernando da; DUARTE, Adriana. Gestão por resultados e participação da comunidade escolar: a experiência da rede municipal de educação de Belo Horizonte. Revista Brasileira de Política e Administração da Educação - Periódico científico editado pela ANPAE, [S.l.], v. 33, n. 3, p. 751 - 769, dez. 2017.

SILVA, Rogério Correia da. Participação e aprendizagem na educação da criança indígena. Rev. Bras. Educ., Rio de Janeiro, v. 19, n. 58, p. 655-670, set. 2014. 


\section{APÊNDICE}

\section{Referências mais utilizadas nos artigos analisados}

As referências apresentadas a seguir foram reunidas neste espaço com o objetivo de explicitar mais claramente as obras citadas no Quadro 1 - Referências mais utilizadas nos artigos. Alguns títulos aparecem mais de uma vez, por terem sido reeditados e/ou reimpressos em outros anos. Contudo, preferimos preservar a relação obra/ano, preservando a representatividade das obras. Ressalva-se que a quantificação das referências foi pautada pelo número de vezes que um(a) determinado(a) autor(a) era citado (a) e, não pelo ano das publicações.

BORDENAVE, Juan E. Diaz. O que é participação? 3. ed. São Paulo: Brasiliense, 1985.

BORDENAVE, Juan E. Diaz. O que é participação. 8. ed. São Paulo: Brasiliense, 1994. (Coleção Primeiros Passos, 95).

CURY, Carlos R. J. O Conselho Nacional de Educação e a gestão democrática: In: OLIVEIRA, Dalila Andrade (Org.). Gestão democrática da educação: desafios contemporâneos. Petrópolis: Vozes, 1997.

CURY, Carlos R. J. O Plano Nacional de Educação: duas formulações. Cadernos de Pesquisa, São Paulo, n 104, p. 162-180, jun. 1998.

DAGNINO, Evelina. Os movimentos sociais e a emergência de uma nova noção de cidadania. In: Anos 90: política e sociedade no Brasil. São Paulo: Brasiliense, 1994.

DAGNINO, Evelina. Sociedade civil, participação e cidadania: de que estamos falando? In: MATO, D. (Org.). Políticas de ciudadanía y sociedad civil en tiempos de globalización. Caracas: FACES; Universidad Central de Venezuela, 2004, p. 95-110.

DAGNINO, Evelina; OLIVEIRA, Alberto; PANFICHI, Aldo (Org.). A disputa pela construção democrática na América Latina. São Paulo: Paz e Terra; Campinas: Unicamp, 2006.

DEMO, Pedro. Participação é conquista. São Paulo: Cortez, 1985. 
DEMO, Pedro. Participação é conquista. São Paulo: Cortez, 1988.

DEMO, Pedro. Participação é conquista: noções de política social participativa. 6. ed. São Paulo, Cortez, 2009.

DOURADO, Luiz F. A escolha de dirigentes escolares: políticas e gestão da educação no Brasil. In: FERREIRA, Naura Syria Carapeto (org.). Gestão democrática da educação: atuais tendências, novos desafios. $2^{a}$ ed. São Paulo: Cortez, 2000. p. 77-95.

DOURADO, Luiz F. Escolha de dirigentes escolares: políticas e gestão da educação no Brasil. In: FERREIRA, Naura Syria Carapeto (org.). Gestão democrática da educação: atuais tendências, novos desafios. 5. ed. São Paulo: Cortez, 2006.

GOHN, Maria da Glória Marcondes. Conselhos populares e participação popular. Serviço Social e Sociedade. São Paulo, s/nº, p. 65-89, 1989.

GOHN, Maria da Glória Marcondes. Conselhos Gestores e participação sociopolítica. São Paulo: Editora Cortez, 2001. (Coleção Questões da nossa época, 84)

GOHN, Maria da Glória Marcondes. Educação não-formal, participação da sociedade civil e estruturas colegiadas nas escolas. Ensaio: Avaliação e Políticas Públicas em Educação, Rio de Janeiro, v. 14, n. 50, p. 27-38, 2006. Disponível em: http://www.scielo.br/pdf/ensaio/v14n50/30405.pdf. Acesso em: 07 abr. 2020.

GOHN, Maria da Glória Marcondes. O protagonismo da sociedade civil: movimentos sociais, ONGs e redes solidárias. 2. ed. São Paulo: Cortez, 2008.

GOHN, Maria da Glória Marcondes. Movimentos e lutas sociais na história do Brasil. 5. ed. São Paulo: Loyola, 2009a.

GOHN, Maria da Glória Marcondes. Movimentos sociais e educação. 7. ed. São Paulo: Cortez, 2009b.

GOHN, Maria da Glória Marcondes. Novas teorias dos movimentos sociais. 2. ed. São Paulo: Loyola, 2009c. 
GOHN, Maria da Glória Marcondes. Educação não formal e o educador social. São Paulo: Cortez, 2010a.

GOHN, Maria da Glória Marcondes. Movimentos sociais e redes de mobilizações civis no Brasil contemporâneo. Petrópolis: Vozes, 2010 b.

GOHN, Maria da Glória Marcondes. Teorias dos movimentos sociais. Paradigmas clássicos e contemporâneos. 9. ed. São Paulo: Loyola, 2011.

LIMA, Licínio. A Escola como Organização e a Participação na Organização Escolar. Um estudo da Escola Secundária em Portugal (1974-1988). Braga: Universidade do Minho/Instituto de Educação e Psicologia, 1998.

LIMA, Licínio. Organização Escolar e a Democracia Radical: Paulo Freire e a governação democrática da escola pública. São Paulo: Cortez Editora, 2000.

LIMA, Licínio. A escola como organização educativa. 2. ed. São Paulo: Cortez, 2003.

PARO, Vitor Henrique. Gestão democrática da escola pública. São Paulo: Ática, 1997.

PARO, Vitor Henrique. Gestão Democrática da escola pública. São Paulo: Ática, 2002.

PARO, Vitor Henrique. Crítica da estrutura da escola. São Paulo: Cortez, 2011.

RANCIÈRE, Jacques. Políticas da escrita. São Paulo: Ed. 34, 1995.

RANCIÈRE, Jacques. O desentendimento: política e filosofia. São Paulo: Ed. 34, 1996.

\section{Tauã Carvalho de Assis}

Mestre em educação (UFG). Doutorando em Educação na Faculdade de Educação da Universidade Estadual de Campinas. Professor da Rede Municipal de Educação de Jataí-Goiás. E-mail: tauacarvalho@hotmail.com 


\section{Maria da Glória Gohn}

Doutora em Ciência Política. Professora titular aposentada da Faculdade de Educação da Universidade Estadual de Campinas. Orientadora no Programa de Pós-Graduação em Educação da Universidade Estadual de Campinas.

E-mail:mgohn@uol.com.br

Recebido em 08 março de 2020

Aprovado em 13 de abril de 2020 